\title{
Article \\ The Profile of Polyphenolic Compounds, Contents of Total Phenolics and Flavonoids, and Antioxidant and Antimicrobial Properties of Bee Products
}

\author{
Tomasz Sawicki $^{1, *(\mathbb{D})}$, Małgorzata Starowicz ${ }^{2} \mathbb{D}$, Lucyna Kłębukowska ${ }^{3} \mathbb{D}$ and Paweł Hanus ${ }^{4}(\mathbb{D}$ \\ 1 Department of Human Nutrition, Faculty of Food Sciences, University of Warmia and Mazury in Olsztyn, \\ 45f Słoneczna Street, 10-718 Olsztyn, Poland \\ 2 Department of Chemistry and Biodynamics of Food, Institute of Animal Reproduction and Food Research of \\ Polish Academy of Sciences, 10 Tuwima Street, 10-748 Olsztyn, Poland; m.starowicz@pan.olsztyn.pl \\ 3 Department of Industrial and Food Microbiology, Faculty of Food Sciences, University of Warmia and Mazury \\ in Olsztyn, Plac Cieszyński 1, 10-726 Olsztyn, Poland; lutkak@uwm.edu.pl \\ 4 Department of Technology and Plant Product Quality Assessment, University of Rzeszów, 4 Zelwerowicza \\ Street, 35-601 Rzeszów, Poland; phanus@ur.edu.pl \\ * Correspondence: tomasz.sawicki@uwm.edu.pl
}

Citation: Sawicki, T.; Starowicz, M.; Kłębukowska, L.; Hanus, P. The Profile of Polyphenolic Compounds, Contents of Total Phenolics and Flavonoids, and Antioxidant and Antimicrobial Properties of Bee Products. Molecules 2022, 27, 1301. https://doi.org/10.3390/ molecules27041301

Academic Editors: Gerson Nakazato and Renata Katsuko Takayama Kobayashi

Received: 17 January 2022

Accepted: 14 February 2022

Published: 15 February 2022

Publisher's Note: MDPI stays neutral with regard to jurisdictional claims in published maps and institutional affiliations.

Copyright: (c) 2022 by the authors. Licensee MDPI, Basel, Switzerland. This article is an open access article distributed under the terms and conditions of the Creative Commons Attribution (CC BY) license (https:/ / creativecommons.org/licenses/by/ $4.0 /)$.

\begin{abstract}
This study aimed to characterize bee products (bee bread, bee pollen, beeswax, and multiflorous honey) with the profile of phenolic compounds, total phenolic (TPC) and flavonoid (TFC) contents, and antioxidant and microbiological properties. The TP and TF contents could be ordered as follows: bee pollen > bee bread > beeswax > honey. The UPLC-PDA-MS/MS analysis allowed identifying 20 polyphenols. Sinapic acid dominated in bee pollen, gallic acid in the bee bread and honey, while pinobanksin was the major compound of beeswax. The data showed that bee pollen and bee bread had a stronger antioxidant potential than honey and beeswax. Moreover, the antibacterial activity of the bee products was studied using 14 bacterial strains. Bee bread's and bee pollen's antimicrobial activity was higher towards Gram-negative strains. In comparison, honey was more potent in inhibiting Gram-positive bacteria. Our study indicates that bee products may represent valuable sources of bioactive compounds offering functional properties.
\end{abstract}

Keywords: antimicrobial activity; antioxidant capacity; bee products; honey; phenolics; flavonoids

\section{Introduction}

Numerous studies have pointed out the high nutritional value and health benefits of such bee products as pollen, bee bread, honey, and beeswax [1-3]. It has been proven that their positive impact on the human body (antioxidant, anti-microbial, anti-fungal, antiinflammatory, etc.) could be related to the high content of specific bioactive compounds. Baltršaityte et al. [4] determined the phenolic composition of Lithuanian honey samples and showed they were rich in $p$-coumaric acid, kaempferol, chrysin, and apigenin. They found a strong correlation between the content of phenolic compounds and their antioxidant activity. Also, Socha et al. [5] found a linear correlation between phenolics content and antioxidant activity in different varieties of Polish honey. Flavonol glycosides of quercetin, isorhamnetin, and kaempferol were determined as major components of the bee pollen [6]. In another study, flavonoid glycosides of 6-methoxyquercetin (patuletin) were also detected in Brazilian pollen samples, together with hydroxycinnamic acid amide derivatives [7].

The antioxidant activity of different bee products has been already measured using different in vitro methods, including 1,1-diphenyl-2-picrylhydrazyl (DPPH), 2,2'-azinobis(3-ethylbenzothiazoline-6-sulfonic acid) (ABTS), and photochemiluminescence (PCL) assays, and reducing activity measured by cupric (CUPRAC) and ferric reducing antioxidant power (FRAP) [8-11]. The strongest antioxidant activity was found for propolis and pollen, followed by honey [9]. Besides antioxidant activity, bee products offer a very high 
antimicrobial potential $[12,13]$. However, all the bioactive properties of bee products vary as affected by the geographical/regional origin, climate changes, and/or cultivation season. According to our previous research, the TPC and antioxidant capacity might also be related to the producer [10].

In the case of honey, the above-mentioned properties depend on their origin and variety as well as harvest season and conditions [14,15]. Available literature shows that the dark-type honeys elicit more health benefits than the light-type ones. Moreover, current studies indicate that multifloral honeys are healthier than monofloral honeys [15]. Honey is the most popular bee product, while bee pollen and bee bread are increasingly consumed as functional food, or superfood, due to their high concentration of bioactive substances [16]. In the case of beeswax, it is widely used in the cosmetic industry and also in the food industry to protect ripened cheeses [17]. Considering the above, it is very important to know the composition and biological activity of bee products that are intended to be used, or are already used, as dietary supplements. This is the first study in the literature to evaluate and compare four different bee products collected from the same hives. Thus, it aimed to characterize the bee products (beeswax, bee bread, bee pollen, and honey) by the profile of phenolic compounds, TPC and TFC, antioxidant activity, and microbiological properties.

\section{Results and Discussion}

\subsection{Total Phenolic Content (TPC) and Total Flavonoid Content (TFC)}

The TPC and TFC in bee bread, bee pollen, beeswax, and honey are presented in Figure 1. The TPC was within the range from $0.47 \pm 0.04$ to $32.52 \pm 2.19 \mathrm{mg} \mathrm{GAE} / \mathrm{g}$, and its highest value was determined in the bee pollen (32.52 $\pm 2.19 \mathrm{mg} \mathrm{GAE} / \mathrm{g})$. Almost four times lower TPC value was determined in the bee bread ( $8.23 \pm 0.24 \mathrm{mg} \mathrm{GAE} / \mathrm{g})$. Significantly $(p<0.05)$ lower TPC values were detected in beeswax and honey, being approximately 46 and 69 times lesser, respectively. In comparison, bee pollen from Italy was characterized by a lower concentration of TPC, ranging from $13.53 \pm 0.40$ to $24.75 \pm 0.78 \mathrm{mg}$ GAE/g depending on the botanical origin of samples [18]. Another Italian research also showed lower TPC values (4.20 \pm 0.40-29.60 $\pm 0.90 \mathrm{mg}$ GAE/g) in bee pollen collected in 2014, and 2015 [19]. Lower TPC values were also detected in the bee pollen collected in the south of Poland (27.03 mg GAE/g) [20]. In the case of bee bread, studies have reported that the TPC of its samples collected in different regions varies from 2.5 to $37.15 \mathrm{mg} \mathrm{GAE} / \mathrm{g}[14,21]$. The results obtained in our study for bee bread $(8.23 \pm 0.24 \mathrm{mg}$ GAE/g) are within this range. Furthermore, according to our recently published results, this bee product obtained from the northeast part of Poland had a lower concentration of phenolic compounds (by $41 \%$ ) [10] compared to the bee bread from the central part of Poland (this study). The total phenolic content of honey was similar to the data reported by Socha et al. [22] for multifloral honey, i.e., TPC between 0.42 and $0.56 \mathrm{mg} \mathrm{GAE} / \mathrm{g}$. Also, similar values to those of the multifloral honey $(0.47 \pm 0.04 \mathrm{mg} \mathrm{GAE} / \mathrm{g})$ obtained from the central part of Poland and analyzed in the present study were found in the multifloral honey from the northeastern Poland (0.49 $\pm 0.02 \mathrm{mg} \mathrm{GAE} / \mathrm{g})$ [10]. In turn, Wesołowska and Dżugan [11] determined almost 2-times lower values of TPC in multifloral honey obtained from the southern Poland, compared to our study. To the best of our knowledge, there is a lack of data on the content of bioactive compounds in beeswax. Our data of TPC are higher than the values reported for Spanish beeswax [23]. However, the other papers showed only the content of polyphenols in the by-products from beeswax recycling process [24].

A similar tendency was observed in the case of the TFC values, which oscillated between $0.07 \pm 0.00$ and $11.77 \pm 0.15 \mathrm{mg} \mathrm{QE} / \mathrm{g}$. The highest TFC value was found for bee pollen $(11.77 \pm 0.15 \mathrm{mg} \mathrm{QE} / \mathrm{g})$, while the lowest one for honey $(0.07 \pm 0.00 \mathrm{mg} \mathrm{QE} / \mathrm{g})$. The TF content in the bee pollen was approximately 60,96 , and $99 \%$ higher than in the bee bread, beeswax, and honey, respectively. The previously published data showed an ambiguous concentration of flavonoids in bee pollen. Rzepecka-Stojko et al. [20] determined a higher level of TFC (20.22 mg QE/g) in the Polish bee pollen, whereas Mayda et al. [14] found only $2.62-4.44 \mathrm{mg} \mathrm{QE} / \mathrm{g}$ of flavonoids in the Turkish bee pollen. In the case of 
bee bread's flavonoids, the Turkish bee bread was characterized by a lower level of these compounds (1.81-3.74 mg QE/g), than the Polish bee bread [14]. However, Zuluga et al. [25] determined a similar TFC in the Colombian bee bread (1.9-4.5 mg QE/g). With regard to the next bee product, the previously published data showed a similar TFC in the Polish multifloral honeys (0.05-0.14 mg QE/g) [22] with those obtained in our study. On the other hand, other multifloral honeys also originating from Poland, had more than 2-times lower level of flavonoids [26]. In the case of beeswax, previously published data indicated a much lower content of flavonoids in beeswax samples from Spain [26]. In addition, flavonoids account for 25 to $75 \%$ of the total polyphenols (TP) in bee products [19]. In our study, the contribution of flavonoids in honey was lower, and constituted about $13 \%$ of TP. The difference in the content of bioactive compounds in honey may be due to their origin $[14,19]$. However, in the case of bee bread, bee pollen, and beeswax, the contribution of TFC was higher than in honey and was approximately 36,27 , and $42 \%$ of TP, respectively. The obtained data indicate that the bee products represent good sources of phenolic and flavonoid compounds. The order of polyphenols content in the bee products was as follows: bee pollen $>$ bee bread $>$ beeswax $>$ honey. To summarize, the various contents of phenolic and flavonoid compounds detected in bee products may result from the three main factors: method of extraction, botanical origin, and location of harvest $[10,14,18,19]$. Mayda et al. [14] demonstrated that TP/TF content varied significantly in the samples of bee bread and bee pollen from the same beehive located in different regions. The range of TPC values for bee bread was from 26.69 to 43.42 (mg GAE/g), and for bee pollen it was from 8.26 to 12.71 (mg GAE/g) [14]. The same tendency was noted for TFC, which varied between 2.62-4.44 mg QE/g in bee-pollen samples. In bee bread, TFC values were not stable either and ranged from 1.81 to $3.74 \mathrm{mg} \mathrm{QE} / \mathrm{g}$. Rocchetti et al. [19] determined the highest TPC in bee pollen with the predominant Daucus and Coriandrum pollen, whereas the lowest one in the samples with preponderance of Magnolia pollen.

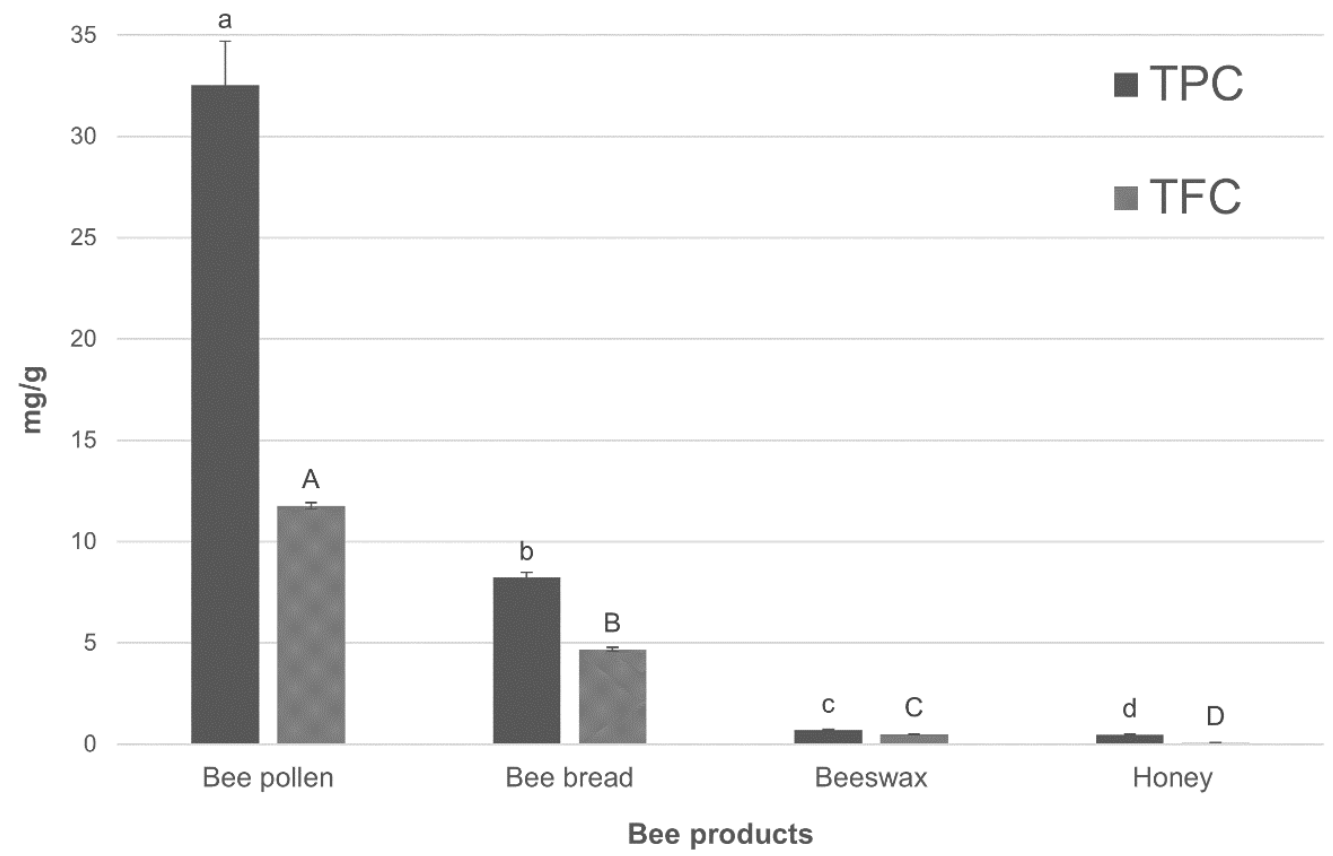

Figure 1. Total phenolic content (TPC) and total flavonoid content (TFC) in bee products. TPC is expressed as mg of gallic acid equivalent (GAE) per gram of sample, while, TF is expressed as mg of quercetin equivalent $(\mathrm{QE})$ per gram. The results for each sample are reported as the mean value of three repetitions. a-d: different letters indicate significant differences of TPC values $(p<0.05)$; A-D: different letters indicate significant differences of TFC values $(p<0.05)$. 


\subsection{Polyphenolic Profile in the Bee Products}

The next stage of this study entailed determinations of the profile and contents of the main phytochemicals in the analyzed bee products. The characterization of the polyphenolic profile was carried out mainly to determine which specific compounds might have the strongest effect upon the antioxidant and anti-microbiological properties of the bee products. Polyphenolics were determined by ultra-performance liquid chromatography coupled with a mass spectrometer (UPLC-PDA-MS/MS), and respective results are presented in Table 1. Twenty compounds were identified in bee products, eleven of which were flavonoids (sakuranetin dimer, rutin, isorhamnetine 3-O-rutinoside, quercetin 3-O-glucuronide, orientin, vitexin, quercetin, epicatechin, kaempferol, pinobanksin, and apigenin), eight represented phenolic acids (gallic, neochlorogenic, chlorogenic, protocatechuic, caffeic, sinapic, 3,4-di-O-caffeoylquinic, and protocatechuic acid-O-hexoside acids), and one compound belonged to ellagitannins (ellagic acid). Previously published data have also shown the presence of three groups of polyphenolic compounds in honey, bee pollen, and bee bread [27].

Table 1. Polyphenolic compounds detected in the bee products using UPLC-PDA-ESI-MS.

\begin{tabular}{|c|c|c|c|c|c|c|}
\hline No. & Compound & $\begin{array}{c}\mathbf{R}_{\mathbf{t}} \\
{[\mathrm{min}]}\end{array}$ & $\begin{array}{l}\text { MS } \\
{[m / z]}\end{array}$ & $\begin{array}{c}\text { MS/MS } \\
{[m / z]}\end{array}$ & $\begin{array}{l}\lambda_{\max } \\
{[\mathrm{nm}]}\end{array}$ & Sample \\
\hline 1 & gallic acid & 1.12 & 169 & 125 & 271 & $\mathrm{H}, \mathrm{BB}, \mathrm{BP}$ \\
\hline 2 & ellagic acid & 1.16 & 301 & $283 / 200 / 175$ & 267 & $\mathrm{H}, \mathrm{BB}, \mathrm{BP}$ \\
\hline 3 & $\begin{array}{c}\text { neochlorogenic } \\
\text { acid }\end{array}$ & 1.71 & 353 & $191 / 179$ & 262 & $\mathrm{H}, \mathrm{BB}, \mathrm{BP}$ \\
\hline 4 & chlorogenic acid & 2.03 & 353 & $191 / 179$ & 281 & $\mathrm{H}, \mathrm{BB}, \mathrm{BP}$ \\
\hline 5 & protocatechuic acid & 2.23 & 153 & 109 & 291 & $\mathrm{H}, \mathrm{BB}, \mathrm{BP}$ \\
\hline 6 & sakuranetin dimer & 3.19 & 551 & $285 / 179 / 164$ & 307 & $\mathrm{H}$ \\
\hline 7 & caffeic acid & 3.96 & 179 & 135 & 300 & $\mathrm{H}$ \\
\hline 8 & rutin & 4.44 & 609 & 301 & $286 / 338$ & $\mathrm{BB}, \mathrm{BP}$ \\
\hline 9 & sinapic acid & 4.73 & 223 & $175 / 164$ & 295 & $\mathrm{H}, \mathrm{BB}, \mathrm{BP}$ \\
\hline 10 & $\begin{array}{c}\text { isorhamnetine } \\
\text { 3-O-rutinoside } \\
\text { 3,4-di-O- }\end{array}$ & 4.76 & 623 & $315 / 314$ & 266,309 & $\mathrm{BB}, \mathrm{BP}$ \\
\hline 11 & $\begin{array}{l}\text { caffeoylquinic } \\
\text { acid }\end{array}$ & 5.09 & 515 & $179 / 191$ & - & W \\
\hline 12 & $\begin{array}{c}\text { quercetin } \\
\text { 3-O-glucuronide }\end{array}$ & 5.35 & 477 & 301 & 269,324 & $\mathrm{BB}, \mathrm{BP}$ \\
\hline 13 & orientin & 5.39 & 447 & $357 / 339$ & 265,316 & $\mathrm{BB}$ \\
\hline 14 & vitexin & 6.12 & 431 & $341 / 311$ & 264,315 & $\mathrm{BB}$ \\
\hline 15 & quercetin & 6.45 & 301 & $179 / 151$ & $256 / 355$ & $\mathrm{H}$ \\
\hline 16 & epicatechin & 7.44 & 289 & $245 / 203$ & 319 & $\mathrm{BB}, \mathrm{BP}$ \\
\hline 17 & $\begin{array}{l}\text { kaempferol } \\
\text { protocatechuic }\end{array}$ & 7.53 & 285 & $257 / 201 / 185$ & 286 & W \\
\hline 18 & $\begin{array}{c}\text { acid- } \\
\text { O-hexoside }\end{array}$ & 8.15 & 315 & 153 & 287 & $\mathrm{BB}, \mathrm{BP}, \mathrm{W}$ \\
\hline 19 & pinobanksin & 8.24 & 271 & $185 / 151$ & 290 & $\mathrm{BB}, \mathrm{BP}, \mathrm{W}$ \\
\hline 20 & apigenin & 8.65 & 269 & $179 / 225$ & $338 / 346$ & W \\
\hline
\end{tabular}

Abbreviation: Rt—retention time; H—honey; BP—bee pollen; BB-bee bread; and W-beeswax.

Each bee product had its unique polyphenol profile, which is shown in Table 2. Gallic, ellagic, neochlorogenic, chlorogenic, protocatechuic, and sinapic acids were detected in honey, bee pollen, and bee bread. Rutin, isorhamnetin 3-O-rutinoside, quercetin 3-O-glucuronide, and epicatechin were found in bee bread and bee pollen. In addition, protocatechuic acid-O-hexoside and pinobanksin were present in the bee bread, bee pollen, and beeswax. However, some compounds were present only in particular bee products. Sakuranetin dimer, caffeic acid, and quercetin were detected only in honey, while orientin and vitexin only in bee bread. Moreover, three compounds (3,4-di-O-caffeoylquinic acid, kaempferol, and apigenin) were found only in beeswax. 
Table 2. Contribution of individual polyphenolic compounds in the bee products.

\begin{tabular}{|c|c|c|c|c|c|}
\hline \multirow{2}{*}{ No. } & \multirow{2}{*}{ Compound } & \multicolumn{4}{|c|}{ Bee Product } \\
\hline & & Bee Pollen & Beebread & Honey & Beeswax \\
\hline 1 & gallic acid & 21.3 & 32.6 & 69.2 & ND \\
\hline 2 & ellagic acid & 2.2 & 2.6 & 6.6 & ND \\
\hline 3 & neochlorogenic acid & 0.9 & 0.7 & 1.5 & ND \\
\hline 4 & chlorogenic acid & 0.7 & 0.8 & 13.2 & ND \\
\hline 5 & protocatechuic acid & 0.1 & 0.8 & 0.2 & ND \\
\hline 6 & sakuranetin dimer & ND & ND & 4.6 & ND \\
\hline 7 & caffeic acid & ND & ND & 0.8 & ND \\
\hline 8 & rutin & 10.0 & 5.1 & ND & ND \\
\hline 9 & sinapic acid & 42.8 & 27.3 & 1.8 & ND \\
\hline 10 & isorhamnetine 3-O-rutinoside & 5.8 & 2.5 & ND & ND \\
\hline 11 & 3.4-di-O-caffeoylquinic acid & ND & ND & ND & 1.9 \\
\hline 12 & quercetin 3-O-glucuronide & 7.9 & 0.3 & ND & ND \\
\hline 13 & orientin & ND & 7.1 & ND & ND \\
\hline 14 & vitexin & ND & 15.2 & ND & ND \\
\hline 15 & quercetin & ND & ND & 2.2 & ND \\
\hline 16 & epicatechin & 7.2 & 2.6 & ND & ND \\
\hline 17 & kaempferol & ND & ND & ND & 6.0 \\
\hline 18 & protocatechuic acid-O-hexoside & 0.2 & 1.6 & ND & 3.4 \\
\hline 19 & pinobanksin & 0.7 & 0.8 & ND & 85.7 \\
\hline \multirow[t]{2}{*}{20} & apigenin & ND & ND & ND & 3.0 \\
\hline & Total $[\mu \mathrm{g} / \mathrm{g}]$ & $79.39 \pm 0.31^{a}$ & $56.27 \pm 0.89^{b}$ & $1.61 \pm 0.02^{c}$ & $0.39 \pm 0.00$ \\
\hline
\end{tabular}

The results for each sample are reported as the mean value of 3 repetitions. a-d: different letters indicate significant differences $(p<0.05)$ within the lines.

Habryka et al. [26] found six phenolic acids (ferulic, gallic, $p$-hydroxybenzoic, caffeic, $p$-coumaric, and protocatechuic acids) and four flavonoids (kaempferol, chrysin, galangin, and quercetin) in Polish multifloral honey. Results of the study conducted by Rzepecka-Stojko et al. [20] showed the presence of six phenolic acids (gallic, caffeic, ferulic, 4-hydroxycinnamic, 4-t-p-coumaric, and $t$-cinnamic acids) and five flavonoids (rutin, myrycithin, quercetin, kaempferol, and isorhamnetin) in bee pollen from the southern part of Poland. In the cited study, the bee pollen did not contain nine compounds (ellagic, neochlorogenic, chlorogenic, protocatechuic, sinapic, and protocatechuic acid-O-hexoside acids, as well as quercetin 3-O-glucuronide, epicatechin, and pinobanksin) detected in the samples examined in our study. In the case of bee bread, the Moroccan's bee bread sample was found to contain thirteen phenolic compounds, mainly flavonols glycoside derivatives, especially quercetin, kaempferol, isorhamnetin, and methylherbacetrin derivatives [28]. In contrast, Isidorov et al. [29] identified using the GC-MS analysis, naringenin, kaempferol, apigenin, isorhamnetin, and quercetin in bee bread from Latvia, Russia, and Poland. In turn, ten phenolic compounds (mainly flavonoids derivatives) have been identified in the beeswax by-products [24].

The highest total content of phenolic acids, expressed as a sum of individual compounds, was detected in bee pollen $(52.51 \mu \mathrm{g} / \mathrm{g})$, followed by bee bread $(35.91 \mu \mathrm{g} / \mathrm{g})$, honey $(1.39 \mu \mathrm{g} / \mathrm{g})$, and beeswax $(0.02 \mu \mathrm{g} / \mathrm{g})$. The main compound among the phenolic acids in the bee pollen was sinapic acid, followed by gallic acid $(42.8 \%$ and $21.3 \%$ of the sum of individual polyphenolic compounds, respectively; Table 2). The available literature data shows that the major phenolic acid in bee pollen was gallic acid [20], and that gallic acid was found to be the dominant phenolic acid in bee bread and honey (32.6 and 69.2\%, respectively). Furthermore, sinapic acid was proved to be the second most abundant compound of bee bread (27.3\%), whereas chlorogenic acid to be the second most dominant phenolic acid of honey (13.2\%). This was an important finding because sinapic, gallic, and chlorogenic acids are indicators of the antimicrobial and antioxidant activities [30,31]. In the case of beeswax, the major phenolic acid was protocatechuic acid-O-hexoside (3.4\%).

In the case of flavonoids, the highest TFC presented as a sum of individual flavonoid compounds was found in bee pollen $(25.18 \mu \mathrm{g} / \mathrm{g})$, followed by bee bread $(18.87 \mu \mathrm{g} / \mathrm{g})$, then beeswax $(0.37 \mu \mathrm{g} / \mathrm{g})$, and honey $(0.11 \mu \mathrm{g} / \mathrm{g})$. The presented data agree with the results 
obtained using the spectrophotometric method presented above. The major flavonoids of bee pollen were rutin ( $10 \%$ of the TFC; Table 2$)$, followed by quercetin 3-O-glucuronide and epicatechin (7.9 and 7.2\%, respectively). These results are consistent with findings reported by Rzepecka-Stojko et al. [20], who identified rutin as the major flavonoid of bee pollen. In the case of bee bread, the dominant flavonoid was vitexin, which accounted for $15.2 \%$ of TFC, and was followed by rutin accounting for $5.1 \%$ of TFC. In comparison, Bayram et al. [32] reported that rutin followed by quercetin were the main flavonoids of the Turkish bee bread. Moreover, these authors did not find vitexin in bee bread, while in our research, quercetin was only present in honey The major flavonoid compound of honey turned out to be sakuranetin dimer which accounted for $4.6 \%$ of the TFC. In the case of beeswax, the main flavonoid was pinobanksin which constituent $85.7 \%$ of the total amount of flavonoids.

The dominant bioactive compounds of bee pollen, bee bread, and honey were phenolic acids, which constituted $66.1 \%, 63.8 \%$, and $86.6 \%$ of the sum of individual polyphenolic compounds. On the other hand, flavonoids were the main group of compounds found in beeswax (94.8\%). Moreover, bee bread shared a common polyphenolic profile with that of the other samples (bee pollen and honey), likely since it is a combination of honey and pollen $[3,10]$. Furthermore, our study indicated that the polyphenols present in bee pollen were more significant contributors to the profile of these compounds of bee bread than these present in honey.

Differences in the polyphenolic profiles and contents can be related to the method of extraction and a less sensitive analytical technique. Moreover, the compound number detected may be related to the region of bee products origin. The previous studies have also shown a relationship between the profile of volatile compounds in bee products and their area of origin [10,32].

\subsection{Antioxidant Activity and Reducing Potential of Bee Products}

The antioxidant activity of the obtained extracts of bee products was measured by the ABTS and DPPH assays and the PCL method, which included two different approaches (hydrophilic and lipophilic conditions). The tested bee products were characterized by other antioxidant activities (Table 3). The order of average antioxidant activity for the bee products was as follows: ABTS > ACL (lipophilic antioxidants) $>$ ACW (hydrophilic antioxidants) $>$ DPPH. Moreover, the antioxidant activity determined by the ABTS assay was highly correlated with the data evaluated by the ACW $(r=0.933)$ and DPPH $(r=0.900)$ methods, and moderately correlated with the ACL values $(r=0.685)$. The antioxidant activity values determined by the DPPH test were highly correlated with the ACW data $(r=0.874)$, and moderately with the ACL values $(r=0.567)$. In addition, the values obtained in the ACW assay were highly correlated with the data measured using the ACL test $(\mathrm{r}=0.882)$.

Table 3. Antioxidant activity (determined using PCL, DPPH, and ABTS assays) and reducing potential (FRAP assay) of bee products.

\begin{tabular}{|c|c|c|c|c|c|}
\hline \multirow{2}{*}{ Parameter/Sample } & \multicolumn{2}{|c|}{ PCL $[\mu \mathrm{mol}$ Trolox/g] } & \multirow{2}{*}{$\begin{array}{c}\text { DPPH } \\
{[\mu \mathrm{mol} \text { Trolox/g] }}\end{array}$} & \multirow{2}{*}{$\begin{array}{c}\text { ABTS } \\
{[\text { mmol Trolox/g] }}\end{array}$} & \multirow{2}{*}{$\begin{array}{c}\text { FRAP } \\
{[\mu \mathrm{mol} \text { Trolox/g] }}\end{array}$} \\
\hline & ACL & ACW & & & \\
\hline Bee pollen & $410.13 \pm 19.56^{b}$ & $129.29 \pm 2.75^{b}$ & $16.97 \pm 1.19^{a}$ & $32.56 \pm 0.30^{\mathrm{a}}$ & $76.94 \pm 4.48^{\mathrm{a}}$ \\
\hline Bee bread & $1017.83 \pm 56.03^{a}$ & $162.16 \pm 2.83^{\mathrm{a}}$ & $10.26 \pm 2.27^{b}$ & $31.60 \pm 0.16^{b}$ & $31.23 \pm 1.96^{\mathrm{b}}$ \\
\hline Beeswax & $210.59 \pm 0.41^{\mathrm{c}}$ & $4.72 \pm 0.04^{c}$ & $0.53 \pm 0.02^{c}$ & $5.96 \pm 0.05^{\mathrm{d}}$ & $8.14 \pm 0.58^{c}$ \\
\hline Honey & $1.53 \pm 0.02^{\mathrm{d}}$ & $4.72 \pm 0.17^{c}$ & $0.18 \pm 0.04^{\mathrm{d}}$ & $15.68 \pm 0.60^{c}$ & $35.36 \pm 1.03^{b}$ \\
\hline
\end{tabular}

The results for each sample are reported as the mean value of 3 repetitions. a-d: different letters indicate significant differences $(p<0.05)$ within the column.

According to the obtained data, bee bread, bee pollen, and beeswax had higher ACL values than ACW, while the importance of ACW was higher only in the honey (Table 3). Bee bread had more than 6-times higher ACL values than the ACW, while the bee pollen had 
3-times higher ACL/ACW contribution. However, the highest ACL/ACW contribution was detected in beeswax, and the ACL value was more than 40-times higher than ACW. The ACL values were in the following order: bee bread $>$ bee pollen $>$ beeswax $>$ honey, whereas ACW values could be ordered as follows: bee bread $>$ bee pollen $>$ beeswax $=$ honey. Bee bread and multifloral honey were also tested by Sawicki et al. [10] for the ability to scavenge superoxide anion radicals $\left(\mathrm{O}^{2-}\right)$. The data showed that bee bread's extracts have a high antioxidative ability due to the content of lipophilic antioxidants (ACL), but the hydrophilic antioxidants (ACW) of bee bread have significantly lower antioxidant status. In the case of honey, a higher antioxidative ability of hydrophilic antioxidants had been noticed in comparison to the honey's lipophilic antioxidants. Moreover, the results for honey are consistent with the findings from other studies examining multifloral Polish honey [11].

The results of the DPPH test showed that the bee pollen possessed the highest antioxidant activity among the examined bee products $(p<0.05)$, which may, presumably, be due to the large number of bioactive compounds detected in bee pollen. Furthermore, such compounds as sinapic acid, gallic acid, and rutin were characterized by high antioxidant activity dominated in this product $[30,31]$. The antioxidant activity of bee bread, beeswax, and honey were approximately 40,97 , and $99 \%$ lower than the antioxidant activity determined by the DPPH method for bee pollen. Our results for the bee pollen are consistent with the data obtained by Rocchetti et al. [19], who determined the DPPH values for bee pollen of various origin to range from 11.9 to $134.7 \mu \mathrm{mol}$ Trolox/g. The obtained multifloral honey DPPH values are slightly lower than those reported by Habryka et al. [26]. Moreover, our data obtained for beeswax was about 3-times lower than those obtained for the Spanish beeswax [23]. However, DPPH values obtained for bee bread, multifloral honey, and bee pollen were difficult to compare with previously published data mainly due to different units of measure adopted $[14,20,21,28]$.

In the ABTS assay case, the highest antioxidant activity value was also obtained for the bee pollen ( $32.56 \pm 0.30 \mathrm{mmol}$ Trolox/g). In addition, the bee bread was found to have an equally high ability to scavenge ABTS radicals $(31.60 \pm 0.16 \mathrm{mmol}$ Trolox/g). The differences between these two bee products were statistically significant. Two-times lower value of antioxidant activity determined in the ABTS assay was obtained for the extracts of honey compared to the bee pollen. On the other hand, the lowest antioxidant activity values examined using the ABTS test were obtained for beeswax $(5.96 \pm 0.05 \mathrm{mmol}$ Trolox/g).

The highest reducing potential determined in the FRAP test was obtained for the bee pollen $(76.94 \pm 4.48 \mu \mathrm{mol}$ Trolox/g; Table 3$)$. The bee bread and honey also featured high reducing potentials. The reducing potential of bee bread extracts was $60 \%$ lower than of the bee pollen ones, while that of the honey extract was lower by $54 \%$. On the other hand, the previously published data indicated that the bee bread was characterized by a higher reducing potential than honey (samples collected in the northwest part of Poland) [10]. Moreover, the lowest reducing potential was noted for beeswax $(8.14 \pm 0.58 \mu \mathrm{mol}$ Trolox/g). This result was more than 9-times lower compared to the bee pollen. It is noteworthy that the reducing potential depends on the content of bioactive compounds, the harvest period, and the origin of bee products [10].

\subsection{Antimicrobial Activity}

The study results demonstrated that three bee products (bee bread, bee pollen, and honey) possessed antimicrobial activity (Table 4). The highest antimicrobial activity was exhibited by beebread, which inhibited the growth of all the tested bacteria at a concentration of 35\% (except Enterococcus faecalis, where the inhibiting effect was observed at its $45 \%$ concentration; Table 4). Stronger antimicrobial properties of bee bread could be related to a high contribution of gallic acid compared to bee pollen and honey, as well as to the presence of vitexin and orientin, which were not detected in the other bee products tested (Table 2). Ivanišová et al. [33] also showed that bee bread from Ukraine was characterized 
by antimicrobial activity against Gram-positive (Bacillus thuringiensis and Staphylococcus aureus), and Gram-negative (Escherichia coli and Salmonella enterica) strains. Among the other bee products tested, bee pollen also showed antimicrobial activity against all strains used in the study, however, its higher concentrations were needed, i.e., $45-90 \%$ against Gram-positive and 35-75\% against Gram-negative bacteria. Kacániová et al. [13] also reported the antimicrobial potential of bee pollen from Slovakia towards various strains (e.g., E. coli, S. aureus, and Listeria monocytogenes), while showed that honey inhibited only some of the tested bacteria and at the concentration of 50-90\%. Other data also reported the antibacterial activity of Polish multifloral honey against strains of E. coli and S. aureus [34]. Moreover, honeys' antimicrobial properties are related to the synergistic effect of hydrogen peroxide and phenolic compounds $[15,35]$. Bee bread and bee pollen elicited a similar inhibiting effect on the growth of the test strains, however, there was a difference in the diameters of the growth inhibition zones between the samples. This difference may be due to different contents and profiles of bioactive compounds, including mainly polyphenols [33]. Moreover, we can conclude that the bee bread and bee pollen's antimicrobial activity was stronger against the Gram-negative strains. In the case of honey, a stronger inhibiting effect was observed against the Gram-positive bacteria. The other researchers have also shown that honeys possess stronger antimicrobial activity against Gram-positive than Gram-negative [15].

Table 4. Diameters of the growth inhibition zones for the Gram-positive and Gram-negative strains formed by the bee products.

\begin{tabular}{|c|c|c|c|c|c|}
\hline \multirow{2}{*}{ Test Strain } & \multirow{2}{*}{$\begin{array}{c}\text { Sample } \\
\text { Concentration [\%] }\end{array}$} & \multicolumn{4}{|c|}{ Diameters of the Growth Inhibition Zones [mm] } \\
\hline & & Honey & Bee Pollen & Bee Bread & Beeswax \\
\hline \multicolumn{6}{|c|}{ Gram-positive strains } \\
\hline \multirow{5}{*}{$\begin{array}{l}\text { Staphylococcus } \\
\text { aureus G3 }\end{array}$} & 90 & $12.0 \pm 0.0^{\mathrm{c}}$ & $16.0 \pm 1.0^{b}$ & $22.0 \pm 2.0^{\mathrm{a}}$ & 0 \\
\hline & 75 & 0 & $14.0 \pm 0.0$ & $18.0 \pm 2.0$ & 0 \\
\hline & 50 & 0 & $12.0 \pm 0.0$ & $16.0 \pm 1.0$ & 0 \\
\hline & 45 & 0 & $12.0 \pm 0.0$ & $14.0 \pm 1.0$ & 0 \\
\hline & 35 & 0 & 0 & $12.0 \pm 0.0$ & 0 \\
\hline \multirow{5}{*}{$\begin{array}{l}\text { Staphylococcus } \\
\text { aureus 629G }\end{array}$} & 90 & $16.0 \pm 1.0$ & $16.0 \pm 1.0$ & $20.0 \pm 2.0$ & 0 \\
\hline & 75 & $14.0 \pm 1.0$ & $14.0 \pm 1.0$ & $18.0 \pm 2.0$ & 0 \\
\hline & 50 & $12.0 \pm 0.0^{b}$ & $12.0 \pm 0.0^{b}$ & $18.0 \pm 1.0^{\mathrm{a}}$ & 0 \\
\hline & 45 & 0 & 0 & $16.0 \pm 1.0$ & 0 \\
\hline & 35 & 0 & 0 & $12.0 \pm 0.0$ & 0 \\
\hline \multirow{5}{*}{$\begin{array}{c}\text { Staphylococcus } \\
\text { aureus ATCC29213 }\end{array}$} & 90 & $16.0 \pm 1.0$ & $18.0 \pm 2.0$ & $18.0 \pm 1.0$ & 0 \\
\hline & 75 & $14.0 \pm 1.0$ & $14.0 \pm 1.0$ & $16.0 \pm 1.0$ & 0 \\
\hline & 50 & $12.0 \pm 0.0^{b}$ & $14.0 \pm 1.0^{\mathrm{a}}$ & $14.0 \pm 1.0^{\mathrm{a}}$ & 0 \\
\hline & 45 & 0 & $12.0 \pm 0.0$ & $12.0 \pm 0.0$ & 0 \\
\hline & 35 & 0 & 0 & $12.0 \pm 0.0$ & 0 \\
\hline \multirow{5}{*}{$\begin{array}{c}\text { Enterococcus faecalis } \\
24\end{array}$} & 90 & 0 & $14.0 \pm 1.0$ & $18.0 \pm 1.0$ & 0 \\
\hline & 75 & 0 & $12.0 \pm 0.0$ & $16.0 \pm 1.0$ & 0 \\
\hline & 50 & 0 & 0 & $14.0 \pm 1.0$ & 0 \\
\hline & 45 & 0 & 0 & $12.0 \pm 0.0$ & 0 \\
\hline & 35 & 0 & 0 & 0 & 0 \\
\hline \multirow{5}{*}{$\begin{array}{l}\text { Enterococcus faecalis } \\
\text { ss1-1 }\end{array}$} & 90 & 0 & $14.0 \pm 1.0$ & $16.0 \pm 1.0$ & 0 \\
\hline & 75 & 0 & $12.0 \pm 0.0$ & $16.0 \pm 1.0$ & 0 \\
\hline & 50 & 0 & 0 & $14.0 \pm 1.0$ & 0 \\
\hline & 45 & 0 & 0 & $12.0 \pm 0.0$ & 0 \\
\hline & 35 & 0 & 0 & 0 & 0 \\
\hline
\end{tabular}


Table 4. Cont.

\begin{tabular}{|c|c|c|c|c|c|}
\hline \multirow{2}{*}{ Test Strain } & \multirow{2}{*}{$\begin{array}{c}\text { Sample } \\
\text { Concentration [\%] }\end{array}$} & \multicolumn{4}{|c|}{ Diameters of the Growth Inhibition Zones [mm] } \\
\hline & & Honey & Bee Pollen & Bee Bread & Beeswax \\
\hline \multirow{5}{*}{$\begin{array}{c}\text { Listeria } \\
\text { monocytogenes } 67\end{array}$} & 90 & $14.0 \pm 1.0^{\mathrm{b}}$ & $12.0 \pm 0.0^{\mathrm{c}}$ & $20.0 \pm 2.0^{\mathrm{a}}$ & 0 \\
\hline & 75 & 0 & 0 & $16.0 \pm 1.0$ & 0 \\
\hline & 50 & 0 & 0 & $14.0 \pm 1.0$ & 0 \\
\hline & 45 & 0 & 0 & $12.0 \pm 0.0$ & 0 \\
\hline & 35 & 0 & 0 & $12.0 \pm 0.0$ & 0 \\
\hline \multirow{5}{*}{$\begin{array}{c}\text { Listeria } \\
\text { monocytogenes } 74\end{array}$} & 90 & 0 & $12.0 \pm 0.0$ & $18.0 \pm 2.0$ & 0 \\
\hline & 75 & 0 & $12.0 \pm 0.0$ & $16.0 \pm 1.0$ & 0 \\
\hline & 50 & 0 & 0 & $14.0 \pm 1.0$ & 0 \\
\hline & 45 & 0 & 0 & $12.0 \pm 0.0$ & 0 \\
\hline & 35 & 0 & 0 & $12.0 \pm 0.0$ & 0 \\
\hline \multirow{5}{*}{$\begin{array}{c}\text { Listeria } \\
\text { monocytogenes } \\
\text { ATCC1912 }\end{array}$} & 90 & $12.0 \pm 0.0^{b}$ & $12.0 \pm 0.0^{b}$ & $16.0 \pm 1.0^{\mathrm{a}}$ & 0 \\
\hline & 75 & 0 & 0 & $14.0 \pm 1.0$ & 0 \\
\hline & 50 & 0 & 0 & $12.0 \pm 0.0$ & 0 \\
\hline & 45 & 0 & 0 & $12.0 \pm 0.0$ & 0 \\
\hline & 35 & 0 & 0 & $12.0 \pm 0.0$ & 0 \\
\hline \multicolumn{6}{|c|}{ Gram-negative strains } \\
\hline \multirow{5}{*}{$\begin{array}{c}\text { Escherichia coli } \\
14169\end{array}$} & 90 & $12.0 \pm 0.0^{\mathrm{c}}$ & $18.0 \pm 2.0^{b}$ & $24.0 \pm 2.0^{\mathrm{a}}$ & 0 \\
\hline & 75 & 0 & $16.0 \pm 2.0$ & $20.0 \pm 2.0$ & 0 \\
\hline & 50 & 0 & $14.0 \pm 1.0$ & $20.0 \pm 2.0$ & 0 \\
\hline & 45 & 0 & $14.0 \pm 1.0$ & $18.0 \pm 1.0$ & 0 \\
\hline & 35 & 0 & $12.0 \pm 0.0$ & $14.0 \pm 1.0$ & 0 \\
\hline \multirow{5}{*}{$\begin{array}{c}\text { Escherichia coli } \\
25922\end{array}$} & 90 & $12.0 \pm 0.0^{b}$ & $20.0 \pm 2.0^{\mathrm{a}}$ & $20.0 \pm 2.0^{a}$ & 0 \\
\hline & 75 & 0 & $18.0 \pm 2.0$ & $20.0 \pm 2.0$ & 0 \\
\hline & 50 & 0 & $14.0 \pm 1.0$ & $18.0 \pm 1.0$ & 0 \\
\hline & 45 & 0 & $14.0 \pm 1.0$ & $16.0 \pm 1.0$ & 0 \\
\hline & 35 & 0 & $12.0 \pm 0.0$ & $14.0 \pm 1.0$ & 0 \\
\hline \multirow{5}{*}{$\begin{array}{c}\text { Escherichia coli } \\
\text { ATCC } 8793\end{array}$} & 90 & 0 & $16.0 \pm 2.0$ & $20.0 \pm 2.0$ & 0 \\
\hline & 75 & 0 & $16.0 \pm 1.0$ & $18.0 \pm 2.0$ & 0 \\
\hline & 50 & 0 & $14.0 \pm 1.0$ & $16.0 \pm 1.0$ & 0 \\
\hline & 45 & 0 & $12.0 \pm 0.0$ & $14.0 \pm 1.0$ & 0 \\
\hline & 35 & 0 & $12.0 \pm 0.0$ & $14.0 \pm 1.0$ & 0 \\
\hline \multirow{5}{*}{$\begin{array}{c}\text { Salmonella } \\
\text { Typhimurium }\end{array}$} & 90 & 0 & $16.0 \pm 1.0$ & $18.0 \pm 1.0$ & 0 \\
\hline & 75 & 0 & $14.0 \pm 1.0$ & $18.0 \pm 1.0$ & 0 \\
\hline & 50 & 0 & $12.0 \pm 0.0$ & $16.0 \pm 1.0$ & 0 \\
\hline & 45 & 0 & $12.0 \pm 0.0$ & $14.0 \pm 1.0$ & 0 \\
\hline & 35 & 0 & $12.0 \pm 0.0$ & $12.0 \pm 0.0$ & 0 \\
\hline \multirow{5}{*}{$\begin{array}{c}\text { Salmonella } \\
\text { Typhimurium } 235\end{array}$} & 90 & 0 & $14.0 \pm 1.0$ & $16.0 \pm 1.0$ & 0 \\
\hline & 75 & 0 & $12.0 \pm 0.0$ & $16.0 \pm 1.0$ & 0 \\
\hline & 50 & 0 & $12.0 \pm 0.0$ & $14.0 \pm 1.0$ & 0 \\
\hline & 45 & 0 & 0 & $12.0 \pm 0.0$ & 0 \\
\hline & 35 & 0 & 0 & $12.0 \pm 0.0$ & 0 \\
\hline \multirow{5}{*}{$\begin{array}{c}\text { Salmonella } \\
\text { Typhimurium } 63\end{array}$} & 90 & 0 & $14.0 \pm 1.0$ & $18.0 \pm 2.0$ & 0 \\
\hline & 75 & 0 & $12.0 \pm 0.0$ & $18.0 \pm 1.0$ & 0 \\
\hline & 50 & 0 & 0 & $16.0 \pm 1.0$ & 0 \\
\hline & 45 & 0 & 0 & $14.0 \pm 0.0$ & 0 \\
\hline & 35 & 0 & 0 & $12.0 \pm 0.0$ & 0 \\
\hline
\end{tabular}

Data are a mean \pm standard deviation $(n=3)$. Statistical analysis was performed for bee products concentration at which at least three samples demonstrated antimicrobial activity. Different letters in the same row indicate statistical significance $(p<0.05)$.

In our study, beeswax did not show any antimicrobial activity. On the other hand, in the studies presented by Kacániová et al. [13], the wax inhibited the growth of different Gram-negative and Gram-positive strains. This difference may be due to the different 
methods of extract preparation (70-99.9\% methanolic or ethanolic extracts used in the cited study). Moreover, the level of bioactive substances presented in Slovakia's beeswax could be higher (data not shown) than in the Polish beeswax.

In the next stage of our study, we selected the bee products with the highest antimicrobial properties to determine their MIC, and the results obtained were expressed as \% of the concentration of the bee pollen or bee bread which inhibited the growth of the test strains (Table 5). As mentioned above, the bee products with the highest antimicrobial activity turned out to be bee pollen and bee bread. Bee bread showed the antibiotic activity towards S. aureus 629G and ATCC29213, L. monocytogenes 74 and ATCC1912, and Salmonella Typhimurium (in concentration $20 \%$, however, the highest results were obtained against the Escherichia coli strain (in concentration 15-20\%). Bakour et al. [28] also reported a high antibiotic activity of beebread towards E. coli, S. aureus, S. Typhimurium, and L. monocytogenes. While bee pollen was characterized by the higher antibiotic activity only towards the E. coli strains (25\%). On the other hand, the analyzed samples elicited the weakest inhibiting effect of S. aureus G3, E. faecalis and L. monocytogenes 67 strains (Table 5).

Table 5. MIC of the bee bread and bee pollen $(\%, v / v)$.

\begin{tabular}{|c|c|c|c|}
\hline \multirow{2}{*}{ No. } & \multirow{2}{*}{ Test Strain } & \multicolumn{2}{|c|}{ Sample } \\
\hline & & Bee Pollen & Bee Bread \\
\hline S1 & Staphylococcus aureus G3 & 50.0 & 50.0 \\
\hline S2 & Staphylococcus aureus 629G & 50.0 & 25.0 \\
\hline S3 & Staphylococcus aureus ATCC29213 & 50.0 & 25.0 \\
\hline S4 & Enterococcus faecalis 24 & 50.0 & 50.0 \\
\hline S5 & Enterococcus faecalis ss $1-1$ & 50.0 & 50.0 \\
\hline S6 & Listeria monocytogenes 67 & 50.0 & 50.0 \\
\hline S7 & Listeria monocytogenes 74 & 50.0 & 25.0 \\
\hline S8 & Listeria monocytogenes ATCC1912 & 50.0 & 25.0 \\
\hline S9 & Escherichia coli 14169 & 25.0 & 15.0 \\
\hline S10 & Escherichia coli 25922 & 25.0 & 15.0 \\
\hline S11 & Escherichia coli ATCC8793 & 25.0 & 20.0 \\
\hline S12 & Salmonella Typhimurium & 50.0 & 25.0 \\
\hline S13 & Salmonella Typhimurium 235 & 50.0 & 25.0 \\
\hline S14 & Salmonella Typhimurium 63 & 50.0 & 25.0 \\
\hline
\end{tabular}

\subsection{Principal Component Analysis (PCA)}

Principal component analysis (PCA) was performed for all samples and variables (TPC, TFC, individual polyphenols, ABTS, DPPH, ACW, ACL, and FRAP-PCA1), as well as between tested strains, TPC, TFC, and individual polyphenols (PCA2) to investigate the correlations between variables and cases. The correlations between the input variables and principal components (PCs) are presented in Figure 2A,B. The first two PCs explained $82.23 \%$ and $85.30 \%$ of the total data variances for PCA1 and PCA2, respectively. The results obtained in PCA1 (Figure 1-A) demonstrated a strong positive correlation between TPC and DPPH and FRAP assays ( $r=0.932$ and 0.917 , respectively), which indicate a close correlation between the content of phenolic compounds in bee products and their antioxidant and reducing properties. These findings are consistent with a study conducted by Tomczyk et al. [36], who also found a highly positive correlation between the TPC in honey and results of the DPPH and FRAP assays. Moreover, the TPC was positively correlated with results of the ABTS and ACW tests $(r=0.736$ and 0.639 , respectively). A highly positive correlation between TFC and the DPPH and a positive correlation between TFC and FRAP, ABTS, and ACW were found as well. Furthermore, a strong correlation was determined between ACL test and contents of protocatechuic acid, orientin, vitexin and protocatechuic acid- $O$-hexoside $(r=0.958,0.925,0.925$, and 0.968 , respectively). It suggests that this lipid-soluble antioxidant plays a synergistic role in increasing the antioxidant potential of bee products. Moreover, a positive correlation was detected between contents of gallic, ellagic, neochlorogenic and chlorogenic acids, and antioxidant properties, as well 
as a negative correlation between antioxidant properties and sakuranetin dimer, caffeic acid, 3,4-di-O-caffeoylquinic acid, quercetin, kaempferol, and apigenin contents. This might be because the concentrations of these compounds in bee products are too low to make them play a meaningful antioxidant role.
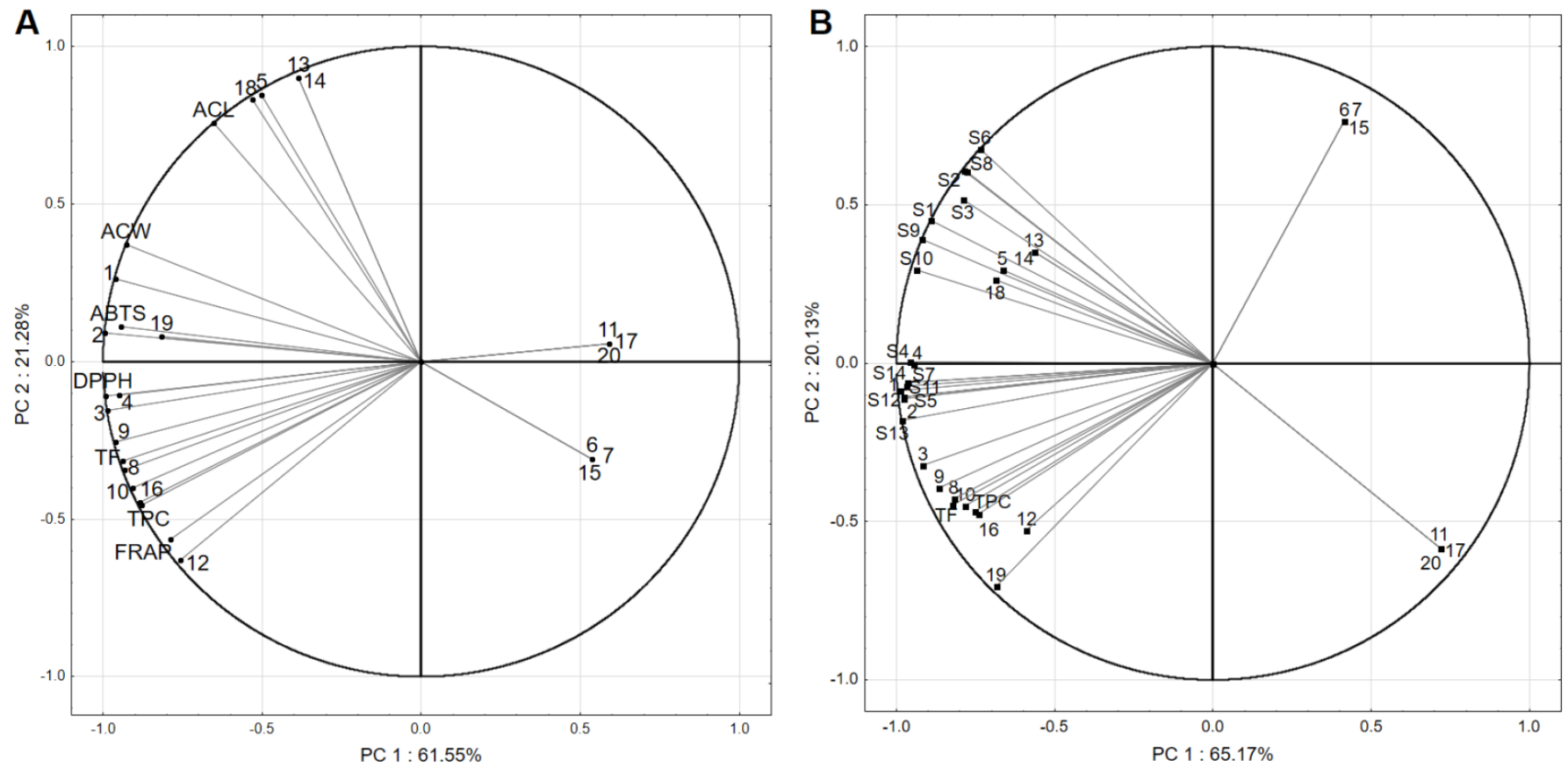

Figure 2. Principal component analysis of TPC, TFC, individual polyphenols, and antioxidant properties (ABTS, DPPH, ACW, ACL, and FRAP) (A), and between tested strains, TPC, TFC, and individual polyphenols (B) (1-20 represent the number of polyphenols identified in the bee products Table 2, while S1-S14 represent the strain used in the study-Table 5).

In PCA2 (Figure 2B), a positive correlation was determined between total phenolic and flavonoid content and microbiological activity as TPC vs. E. faecalis $24(\mathrm{r}=0.630)$, TPC vs. E. faecalis ss1-1 ( $\mathrm{r}=0.690)$, TPC vs. E. coli ATCC8793 $(\mathrm{r}=0.644)$, and TPC vs. all $S$. Typhimurium bacteria $(r=0.630-0.698)$. Moreover, a similar observation of relationships was made for microbiological activity and TFC, however, the correlation coefficients were higher and ranged from $r=0.739$ (for E. faecalis 24 and $S$. Typhimurium 63) to 0.797 (for $S$. Typhimurium). The results obtained indicate that the phenolic and flavonoid compounds present in bee products (mostly beebread and bee pollen) affect the growth and metabolism of bacteria. Moreover, their antimicrobial activity was stronger against Gram-negative strains than the Gram-positive ones. In addition, previously published data also have shown the antimicrobial properties of polyphenolics present in bee products [28,33,34]. The highest positive correlation was achieved between the tested strains and contents of gallic, ellagic, neochlorogenic, chlorogenic, and protocatechuic acids ( $r=0.450-0.999)$. The highest mean value of the " $r$ " coefficient was determined for gallic acid $(r=0.880)$, followed by ellagic acid ( $r=0.846)$, chlorogenic acid $(r=0.845)$, neochlorogenic acid $(r=0.743)$, and protocatechuic acid $(r=0.707)$. In contrast, a negative correlation was detected between microbial activity and contents of 3,4-di-O-caffeoylquinic acid, kaempferol, and apigenin. As with their contribution to the antioxidant activity, these compounds are not present in significant concentrations in bee products to play an important role against growing bacteria. In addition, these three compounds were only present in beeswax, which did not show any antimicrobial properties. Moreover, data obtained shows that phenolic acids rather than flavonoids are the main drivers of the microbial properties of bee products.

The mechanism of the synergistic effect of phytochemicals from bee products needs to be more extensively investigated. Dai, Chen, and Zhou [37] proposed the antioxidant 
synergistic effect of polyphenols extracted from green tea, which regenerated the antioxidant power of tocopherol, and, therefore, antioxidant activity of tea chemicals was renewed by ascorbic acid. In the next step, the antioxidant and microbial activities of fractionated and isolated polyphenols of each bee product could be compared with the activity of their whole extracts, to study the synergistic effect as it was previously described by Herranz-López et al. [38]. By their study, they proved the synergistic effect of polyphenols extracted from Hibiscus sabdariffa against the formation of oxidative species and adipokine secretion [38]. The characteristics of bioactive substances, antioxidant, and antimicrobial properties of the bee products can be helpful for the future research focused on the better utilization of bee products as natural therapeutic agents. The study of Tang et al. [39] on honey/SA/PVA nanofibrous membranes, offers the prospect of using honey as a wound dressing. Moreover, the addition of honey to nanofibers effectively inhibited the growth of both Gram-positive and Gram-negative bacteria. Increasingly advanced research techniques and technologies for the processing and isolation of bioactive compounds also provide opportunities to apply bee products to food as preservatives and agents protecting our health [27]. Thus, there is a need for further research into bee products, their interconnections, and their possible use in medicine, cosmetics, and nutraceuticals.

\section{Materials and Methods}

\subsection{Chemicals and Reagents}

2,2'-Azobis(2-amidonopropane) hydrochloride (AAPH), 2,2'-azinobis(3-ethylbenzothi -azoline-6-sulphonic acid) diammonium salt (ABTS), 2,2-diphenyl-1-picrylhydrazyl (DPPH) and 6-hydroxy-2,5,7,8-tetramethylchroman-2-carboxylic acid (Trolox); Folin-Ciocalteu's phenol reagent; 2,4,6-tris(2-pirydylo)-1,3,5-triazyn (TPTZ); iron (III) chloride hexahydrate; sodium acetate; acetic and hydrochloric acid, gallic acid and quercetin were purchased from Sigma (Sigma Chemical Co., St. Louis, MO, USA). PCL kits for lipophilic (ACL) and hydrophilic antioxidants (ACW) were bought from Analytik Jena (Leipzig, Germany). Reagents of HPLC-MS grade, including acetonitrile, methanol, water, and formic acid, were purchased from Sigma Chemical Co. (St. Louis, MO, USA).

\subsection{Research Material}

Beebread, bee pollen, beeswax and multiflorous honey were obtained from the apiary settled in the Kujawy region (central of Poland) by a professional beekeeper. The bee product samples were collected in the year 2019. Samples were packed in polypropylene bags and kept in refrigeration at $4{ }^{\circ} \mathrm{C}$ before analysis.

\subsection{Extraction of Polyphenols}

The bee product samples were extracted according to the method described by Wilczyńska [40] with some modifications. Briefly, $0.5 \mathrm{~g}$ of samples were vigorously mixed by $5 \mathrm{~min}$ with $5 \mathrm{~mL}$ of the methanol/water mixture $(80: 20, v / v)$ and centrifuged $(14,000 \mathrm{RPM}$, Micro Star 30R, VWR, Radnor, PA, USA) for $10 \mathrm{~min}$ at $4{ }^{\circ} \mathrm{C}$. Then extracts have been stored at $-20{ }^{\circ} \mathrm{C}$ until the analysis.

\subsection{Identification and Quantification of Polyphenols}

The analysis was performed according to the method described by Tomczyk et al. [36]. Briefly, polyphenolic compounds were analyzed using the UPLC-PDA-MS/MS Waters ACQUITY system (Waters, Milford, MA, USA). The polyphenolic detection and identification were based on specific PDA spectra, mass-to-charge ratio, and fragment ions obtained after collision-induced dissociation (CID). The quantitative analysis was based on specific MS transitions in a multiple reaction monitoring (MRM) mode (Table 1). Quantification was achieved by the injection of solutions of known concentrations of phenolic compounds as standards $(\mathrm{R} \leq 0.999)$. All determinations were performed in triplicate and expressed as $\mu \mathrm{g} / \mathrm{g}$. 


\subsection{Determination of Total Phenolics and Flavonoids Content (TPC, TFC)}

The measurements of TPC and TF contents were performed in microplates (Infinite M1000 Pro Multimode Microplate Reader; Tecan Männedorf, Switzerland) according to the procedure described previously by Horszwald and Andlauer [41]. The results were calculated as milligram (mg) of gallic acid equivalent (GAE) per gram of sample for TPC, and as $\mathrm{mg}$ of quercetin equivalent (QE) per gram for TFC.

\subsection{Determination of Antioxidant Activity (DPPH, ABTS, and PCL) and Reducing Potential (FRAP)}

The DPPH scavenging activity was determined with a method described by BrandWilliams et al. [42]. A decrease in the absorbance of the solution obtained was monitored at $517 \mathrm{~nm}$ using an Infinite M1000 PRO plate reader (Tecan Group AG, Männedorf, Switzerland). Results were presented as $\mu \mathrm{mol}$ Trolox per gram of sample. The ABTS test described by Horszwald and Andlauer [41] was used to determine bee product extract's antioxidant activity. Measurements were carried out using the plate reader. The antioxidant activity was expressed as mmol Trolox/g sample. The PCL method with the Photochem apparatus (Analytik Jena, Leipzig, Germany) was used to measure antioxidants' effectiveness against superoxide anion radicals. Antioxidant activity was analyzed using the ACW (antioxidative capacities of water-soluble compounds) and ACL (antioxidative capacities of lipid-soluble compounds) kits. The assay was conducted as previously described by Sawicki et al. [10]. The data obtained was presented as $\mu \mathrm{mol}$ Trolox per gram of sample.

The reducing power was determined using the FRAP assay according to Horszwald and Andlauer [41]. The mixture's absorbance was measured at $593 \mathrm{~nm}$ after $5 \mathrm{~min}$ reaction using a microplate reader. The FRAP method is based on the reduction of ferric ion by antioxidant compounds.

\subsection{AntimicrobialActivity}

\subsubsection{Determination of Antimicrobial Activity by the Well Method}

The antimicrobial activity in all the analyzed bee products was determined with the agar well diffusion method as described previously [15]. The test strains originated from a collection of strains maintained at the Department of Industrial and Food Microbiology of the University of Warmia and Mazury in Olsztyn, Poland. Diameters of the inhibition zones of the growth of test Gram-positive and Gram-negative strains induced by the bee bread, bee pollen, beeswax, and honey were identified. Solutions of the analyzed samples were prepared in sterile conical flasks. The following concentrations of the solutions were made: $35,45,50,75$, and $90 \%$. Surface cultures $\left(10^{4}-10^{5} \mathrm{CFU} / \mathrm{mL}\right)$ of the test strains were started on sterile Petri dishes filled with $20 \mathrm{~mL}$ of a nutrient agar growth medium (Merck, Darmstadt, Germany). Next, wells (10 $\mathrm{mm}$ in diameter) were made with sterile borer into agar plates containing the bacterial inoculum and filled with the prepared solutions of the analyzed samples, each in an amount of $0.7 \mathrm{~mL}$. The plates were incubated at $37^{\circ} \mathrm{C}$ for $24 \mathrm{~h}$. After the incubation, the diameters of the inhibition zones of the growth of the test strains around the wells were determined. The experiment was performed in triplicate.

\subsubsection{Determination of Minimum Inhibitory Concentration (MIC)}

The MIC, i.e., the lowest concentration of honey inhibiting the growth of a test strain, was identified in the bee products which showed the highest antimicrobial activity [15]. The test was made by performing subsequent dilutions (the tested ranges were $100 \%, 50 \%$, $25 \%, 12.5 \%, 6.25 \%$, etc.) of bee bread and bee pollen in a liquid stock medium (Antibiotic Medium Broth, Merck, Darmstadt, Germany). $1 \mathrm{~mL}$ of the growth medium was transferred to each of the test tubes, which were then inoculated with a $24 \mathrm{~h}$ culture of the test strains with $10^{4}$ cells $/ \mathrm{mL}$ inoculum in an amount of $0.1 \mathrm{~mL}$. The samples were incubated for $24 \mathrm{~h}$ at $37^{\circ} \mathrm{C}$. After incubation, it was determined whether there was an increase in the test strain by plating the cultures by the surface method on selective media for the given test strains (TBX for E. coli, Slanetz'a Bartley'a for Enterococcus sp., XLD for Salmonella sp., Baird Parker'a for S. aureus, and ALOA for Listeria monocytogenes). 


\subsection{Statistical Analysis}

The data are presented as mean values \pm standard deviations of triplicate measurement. The differences between samples were analyzed by a one-way ANOVA with LSD Fisher's post hoc test $(p<0.05)$. The Pearson correlation test for correlation analysis was used. Furthermore, data related to antioxidant properties, microbial activity $(90 \%$ of sample concentration was used), contents of individual polyphenolic compounds, TPC, and TFC were subjected to principal component analysis (PCA). The statistical analysis was performed using STATISTICA 13.0 software (StatSoft Inc., Tulsa, OK, USA).

\section{Conclusions}

As previously mentioned, this is the first study that presents the composition of polyphenolics in four different bee products obtained from the same batch. The TPC and TFC, and concentrations of individual polyphenolics varied significantly among the bee products tested. The highest level of bioactive substances was noted in the bee pollen compared to the bee bread, honey, and beeswax. Furthermore, the polyphenols present in bee pollen were found to be the major contributors to its high antioxidant activity. Moreover, each bee product was characterized by specific antimicrobial properties correlated with TPC, TFC, and individual polyphenolic content. Principal component analysis (PCA) results showed that the antioxidant activity determined by DPPH and ABTS assays might be related to (the synergistic effect) the content of ellagic, neochlorogenic and chlorogenic acids, and pinobanksin. Whereas, protocatechuic acid-O-hexoside and protocatechuic acid may be attributable to the combined/synergistic effect of antioxidant activity determined by the ACL assay, while gallic acid may be responsible for the antioxidant activity determined by the ACW assay. The reducing potential (FRAP assay) of the samples may be attributable to the combined/synergistic effect of quercetin 3-O-glucuronide as well as TPC. On the other hand, the same statistical analysis showed that the antimicrobial properties of the honey, bee pollen, and bee bread may be related to the synergistic effect of gallic acid, ellagic acid, chlorogenic acid, protocatechuic acid, orientin, vitexin, and protocatechuic acid-Ohexoside. Thus, bee products, especially bee pollen and bread, could be recommended to be attractive food additives to enhance food rich in bioactive components and with the possibility to increase products' functional properties.

Author Contributions: Conceptualization, T.S. and M.S.; methodology, T.S., M.S., L.K. and P.H.; formal analysis, T.S., M.S., L.K. and P.H.; investigation, T.S., M.S., L.K. and P.H.; writing-original draft preparation, T.S. and M.S.; writing-review and editing, T.S.; visualization, T.S. All authors have read and agreed to the published version of the manuscript.

Funding: This research received funding from the Polish Minister of Education and Science in the range of the program entitled "Regional Initiative of Excellence" for the years 2019-2022, Project No 010/RID/2018/19, amount of funding 12,000,000 PLN.

Institutional Review Board Statement: Not applicable.

Informed Consent Statement: Not applicable.

Data Availability Statement: Not applicable.

Conflicts of Interest: The authors declare no conflict of interest.

Sample Availability: Not applicable.

\section{References}

1. Kieliszek, M.; Piwowarek, K.; Kot, A.M.; Błażejak, S.; Chlebowska-Śmigiel, A.; Wolska, I. Pollen and bee bread as a new health-oriented products: A review. Trends Food Sci. Technol. 2018, 71, 170-180. [CrossRef]

2. Cornara, L.; Biagi, M.; Xiao, J.; Burlando, B. Therapeutic properties of bioactive compounds from different honeybee products. Front. Pharmacol. 2017, 8, 412. [CrossRef] [PubMed]

3. Denisow, B.; Denisow-Pietrzyk, M. Biological and therapeutic properties of bee pollen: A review. J. Sci. Food Agric. 2016, 96, 4303-4309. [CrossRef] 
4. Baltršaitytè, V.; Rimantas Veskutonis, P.; Čeksterytè, V. Radical scavenging activity of different floral origin honey and beebread phenolic extracts. Food Chem. 2007, 101, 502-514. [CrossRef]

5. Socha, R.; Juszczak, L.; Pietrzyk, S.; Gałkowska, D.; Fortuna, T.; Witczak, T. Phenolic profile and antioxidant properties of Polish honeys. Int. J. Food Sci. Technol. 2011, 46, 528-534. [CrossRef]

6. Mosić, M.; Trifković, J.; Vovk, I.; Gašić, U.; Tešić, Ž.; Šikoparija, B.; Milojković-Opsenica, D. Phenolic composition influences the health-promoting potential of bee-pollen. Biomolecules 2019, 26, 783. [CrossRef]

7. Negri, G.; Teixeira, E.W.; Alves, M.L.; Moreti, A.C.; Otsuk, I.P.; Borguini, R.G.; Salatino, A. Hydroxycinnamic acid amide derivatives, phenolic compounds and antioxidant activities of extracts of pollen samples from Southeast Brazil. J. Agric. Food Chem. 2011, 59, 5516-5522. [CrossRef]

8. Martinello, M.; Mutinelli, F. Antioxidant activity in bee products: A review. Antioxidants 2021, 10, 71. [CrossRef]

9. Saral, Ö.; Kiliçarslan, M.; Şahin, H.; Yildiz, O.; Dinçer, B. Evaluation of antioxidant activity of bee products of different bee races in Turkey. Turk. J. Vet. Anim. Sci. 2019, 43, 441-447. [CrossRef]

10. Sawicki, T.; Baczek, N.; Starowicz, M. Characterisation of the total phenolic, vitamins $\mathrm{C}$ and E content and antioxidant properties of the beebread and honey from the same batch. Czech. J. Food Sci. 2020, 38, 158-163. [CrossRef]

11. Wesołowska, M.; Dżugan, M. The use of PHOTOCHEM device in evaluation of antioxidant activity of Polish honey. Food Anal. Methods 2017, 10, 1568-1574. [CrossRef]

12. Felicioli, A.; Cilia, G.; Mancini, S.; Turchi, B.; Galaverna, G.; Cirlini, M.; Cerri, D.; Frantini, F. In vitro antibacterial activity and volatile characterization of organic Apis mellifera ligustica (Spinola, 1906) beeswax ethanol extracts. Food Biosci. 2019, $29,102-109$. [CrossRef]

13. Kacániová, M.; Vuković, N.; Chlebo, R.; Haščik, P.; Cubon, J.; Dżugan, M.; Pasternakiewicz, A. The antimicrobial activity of honey, bee pollen loads and beeswax from Slovakia. Arch. Biol. Sci. 2012, 64, 927-934. [CrossRef]

14. Mayda, N.; Özkök, A.; Ecem Bayram, N.; Gerçek, Y.C.; Sorkun, K. Bee bread and bee pollen of different plant sources: Determination of phenolic content, antioxidant activity, fatty acid and element profiles. J. Food Meas. Charact. 2020, 14, 1795-1809. [CrossRef]

15. Gośliński, M.; Nowak, D.; Kłębukowska, L. Antioxidant properties and antimicrobial activity of manuka honey versus Polish honeys. J. Food Sci. Technol. 2020, 57, 1269-1277. [CrossRef]

16. Kafantaris, I.; Amoutzias, G.D.; Mossialos, D. Foodomics in bee product research: A systematic literature review. Eur. Food Res Technol. 2021, 247, 309-331. [CrossRef]

17. Fratini, F.; Cilia, G.; Turchi, B.; Felicioli, A. Beeswax: A minireview of its antimicrobial activity and its application in medicine. Asian Pac. J. Trop. Med. 2016, 9, 839-843. [CrossRef]

18. Gabriele, M.; Parri, E.; Felicioli, A.; Sagona, S.; Pozzo, L.; Biondi, C.; Domenici, V. Phytochemical composition and antioxidant activity of Tuscan bee pollen of different botanic origins. Ital. J. Food Sci. 2015, 27, 248-259.

19. Rocchetti, G.; Castiglioni, S.; Maldarizzi, G.; Carloni, P.; Lucini, L. UHPLC-ESI-QTOF-MS phenolic profiling and antioxidant capacity of bee pollen from different botanical origin. Int. J. Food Sci. Technol. 2018, 54, 335-346. [CrossRef]

20. Rzepecka-Stojko, A.; Stojko, J.; Kurek-Górecka, A.; Górecki, M.; Sobczak, A.; Stojko, R.; Buszman, E. Polyphenol content and antioxidant activity of bee pollen extracts from Poland. J. Apic. Res. 2015, 54, 482-490. [CrossRef]

21. Čeksteryté, V.; Kurtinaitienè, B.; Venskutonis, P.R.; Pukalskas, A.; Kazernavičiūtè, R.; Balžekas, J. Evaluation of antioxidant activity and flavonoid composition in differently preserved bee products. Czech. J. Food Sci. 2016, 34, 133-142. [CrossRef]

22. Socha, R.; Habryka, C.; Juszczak, L. Effect of propolis as additive on content of selected phenolic compounds and antioxidant activity of honey. Food Sci. Technol. Qual. 2016, 23, 127-139.

23. Navarro-Hortal, M.D.; Orantes-Bermejo, F.J.; Sánchez-González, C.; Varela-López, A.; Giampieri, F.; Torres Fernández-Piñar, C.; Serra-Bonvehí, J.; Forbes-Hernández, T.Y.; Reboredo-Rodríguez, P.; Llopis, J.; et al. Industrial-scale decontamination procedure effects on the content of acaricides, heavy metals and antioxidant capacity of beeswax. Molecules 2019, 24, 1518. [CrossRef] [PubMed]

24. Giampieri, F.; Quiles, J.; Orantes-Bermejo, F.J.; Gasparrini, M.; Forbes-Hernández, T.; Sánchez-González, C.; Llopis, J.; RivasGarcía, L.; Afrin, S.; Varela-López, A.; et al. Are by-products from beeswax recycling process a new promising source of bioactive compounds with biomedical properties? Food Chem. Toxicol. 2018, 112, 126-133. [CrossRef] [PubMed]

25. Zuluaga, C.M.; Serratob, J.C.; Quicazana, M.C. Chemical, nutritional and bioactive characterization of Colombian bee-bread. Chem. Eng. Trans. 2015, 43, 175-180.

26. Habryka, C.; Socha, R.; Juszczak, L. Effect of bee pollen addition on the polyphenolic content, antioxidant activity, and quality parameters of honey. Antioxidants 2021, 10, 810. [CrossRef]

27. Yucel, B.; Topal, E.; Kosoglu, M. Bee products as functional food. In Superfood and Functional Food-An Overview of Their Processing and Utilization; Waisundara, V., Shiomi, N., Eds.; IntechOpen: Rijeka, Croatia, 2017.

28. Bakour, M.; Fernandes, A.; Barros, L.; Sokovic, M.; Ferreira, I.C.F.R.; Iyoussi, B. Bee bread as a functional product: Chemical composition and bioactive properties. LWT-Food Sci. Technol. 2019, 109, 276-282. [CrossRef]

29. Isidorov, V.A.; Isidorova, A.G.; Sczczepaniak, L.; Czyżewska, U. Gas chromatographic-mass spectrometric investigation of the chemical composition of beebread. Food Chem. 2009, 115, 1056-1063. [CrossRef]

30. Sieniewska, E.; Baj, T.; Los, R.; Skalicka-Wozniak, K.; Malm, A.; Glowniak, K. Phenolic acids content, antioxidant and antimicrobial activity of Ligusticum mutellina L. Nat. Prod. Res. 2013, 27, 1108-1110. [CrossRef] 
31. Wang, Y.; Xie, M.; Ma, G.; Fang, Y.; Yang, W.; Ma, N.; Fang, D.; Hu, Q.; Pei, F. The antioxidant and antimicrobial activities of different phenolic acids grafted onto chitose. Carbohydr. Polym. 2019, 225, 115238. [CrossRef]

32. Bayram, N.E.; Gercek, Y.C.; Celik, S.; Mayda, N.; Kostic, A.Z.; Dramicanin, A.M.; Ozkok, A. Phenolic and free aino acid profiles of bee bread and bee pollen with the same botanical origin-similarities and differences. Arab. J. Chem. 2021, 14, 103004. [CrossRef]

33. Ivanišová, E.; Kačániová, M.; Frančáková, H.; Petrová, J.; Hutková, J.; Brovarskyi, V.; Velychko, S.; Adamczuk, L.; Schubertová, Z.; Musilova, J. Bee bread-perspective source of bioactive compounds for future. Potravinarstvo 2015, 9, 592-598. [CrossRef]

34. Dżugan, M.; Grabek-Lejko, D.; Sidor, E.; Tomczyk, M. The impact of ultrasound decrystallization on enzymatic, antioxidant and antibacterial properties of honey. Innov. Food Sci. Emerg. Technol. 2021, 71, 102709. [CrossRef]

35. Dżugan, M.; Grabek-Lejko, D.; Swacha, S.; Tomczyk, M.; Bednarska, S.; Kapusta, I. Physicochemical quality parameters, antibacterial properties and cellular antioxidant activity of Polish buckwheat honey. Food Biosci. 2020, 34, 100538. [CrossRef]

36. Tomczyk, M.; Miłek, M.; Sidor, E.; Kapusta, I.; Litwińczuk, W.; Puchalski, C.; Dżugan, M. The effect of adding the leaves and fruits of Morus alba to rape honey on its antioxidant properties, polyphenolic profile, and amylase activity. Molecules 2020, $25,84$. [CrossRef] [PubMed]

37. Dai, F.; Chen, W.F.; Zhou, B. Antioxidant synergism of green tea polyphenols with alpha-tocopherol and L-ascorbic acid in SDS micelles. Biochimie 2008, 90, 1499-1505. [CrossRef]

38. Herranz-López, M.; Fernández-Arroyo, S.; Pérez-Sanchez, A.; Barrajón-Catalán, E.; Beltrán-Debón, R.; Menéndez, J.A.; AlonsoVillaverde, C.; Segura-Carretero, A.; Joven, J.; Micol, V. Synergism of plant-derived polyphenols in adipogenesis: Perspectives and implications. Phytomedicine 2012, 19, 253-261. [CrossRef]

39. Tang, Y.; Lana, X.; Lianga, C.; Zhonga, Z.; Xiea, R.; Zhoua, Y.; Miaoa, X.; Wangc, H.; Wangd, W. Honey loaded alginate/PVA nanofibrous membrane as potential bioactive wound dressing. Carbohydr. Polym. 2019, 219, 113-120. [CrossRef]

40. Wilczyńska, A. Phenolic content and antioxidant activity of different types of Polish honey-A short report. Pol. J. Food Nutr. Sci. 2010, 60, 309-313.

41. Horszwald, A.; Andlauer, W. Characterisation of bioactive compounds in berry juices by traditional photometric and modern microplate methods. J. Berry Res. 2011, 1, 189-199. [CrossRef]

42. Brand-Williams, W.; Cuvelier, M.E.; Berset, C. Use of a free radical method to evaluate antioxidant activity. LWT-Food Sci. Technol. 1996, 28, 25-30. [CrossRef] 